\title{
Antibiofilm Activity of Cellobiose Dehydrogenase Enzyme (CDH) Isolated from Aspergillus niger on Biofilm of Clinical Staphylococcus epidermidis and Pseudomonas aeruginosa Isolates
}

\author{
Ramin Rasouli ${ }^{1}$, Masoumeh Navidinia (iD ${ }^{2,}{ }^{*}$, Masoomeh Shams Ghahfarokhi ${ }^{3}$, Rouhollah Vahabpour \\ Roudsari $^{2}$, Saadat Adabian ${ }^{2}$ and Ahmad Reza Baghestani ${ }^{4}$ \\ ${ }^{1}$ Department of Microbial Biotechnology, Faculty of Basic Sciences and Advanced Technologies in Biology, University of Science and Culture, Tehran, Iran \\ ${ }^{2}$ Department of Medical Laboratory Sciences, School of Allied Medical Sciences, Shahid Beheshti University of Medical Sciences, Tehran, Iran \\ ${ }^{3}$ Department of Mycology, Faculty of Medical Sciences, Tarbiat Modares University, Tehran, Iran \\ ${ }^{4}$ Physiotherapy Research Center, Department of Biostatistics, Faculty of Paramedical Sciences, Shahid Beheshti University of Medical Sciences, Tehran, Iran \\ "Corresponding author: Department of Medical Laboratory Sciences, School of Allied Medical Sciences, Shahid Beheshti University of Medical Sciences, Tehran, Iran. Email: \\ dr.navidinia@sbmu.ac.ir
}

Received 2019 February 13; Revised 2020 January 21; Accepted 2020 February 01.

\begin{abstract}
Background: It is estimated that more than $80 \%$ of cases of human infections are related to biofilm formation by invasive bacteria. So, in this study, we considered the activity of cellobiose dehydrogenase enzyme (CDH) isolated from Aspergillus niger, as an antibiofilm agent, on biofilm of clinical Staphylococcus epidermidis and Pseudomonas aeruginosa isolates.

Methods: In this study, five standard strains of Aspergillus niger were purchased for CDH production. Of the 42 isolated bacterial strains, 24 strains were Staphylococcus epidermidis and 18 strains were Pseudomonas aeruginosa. Zymogram method was used for screening of $\mathrm{CDH}$. The $\mathrm{CDH}$ activity was measured by monitoring the decrease in absorbance of 2, 6-dichlorophenolindophenol (DCPIP) spectrophotometrically. After cultivation and production of bacterial biofilms, 7 concentrations of the cellobiose prepared and CDH enzyme with a final concentration of $364 \mathrm{U} / \mathrm{mL}$ were considered on bacterial biofilms by microbroth dilution method. Results: Out of five standard strains of Aspergillus niger, only 1 strain have the highest production of CDH. The most effective dilution of cellobiose on growth inhibition of Staphylococcus epidermidis and Pseudomonas aeruginosa in liquid cultures as a function of cellobiose concentration in the presence of cellobiose dehydrogenase was in $12.5 \mu \mathrm{g} / \mathrm{mL}$.

Conclusions: Based on the results of this study, it can be concluded that the CDH enzyme had a high potential for use as an antimicrobial agent. As shown, this enzyme had a high potential for eliminating bacterial biofilms. So, these results may provide a basis for alternative therapies for the treatment of infections related to clinical biofilm producing bacteria.
\end{abstract}

Keywords: Biofilm, Cellobiose Dehydrogenase (CDH), Aspergillus niger, Staphylococcus epidermidis, Pseudomonas aeruginosa

\section{Background}

In nature, bacteria are found in two forms of planktonic and biofilm. Basically, biofilm represents a microbial community in which there are interconnections between different groups. Biofilm can be formed from a different microbial species and on different levels from viable to inert. Different conditions, such as nutrient concentrations, microbial population composition, and hydrodynamic conditions (laminar or turbulent streams), can affect the structure of biofilms. Microorganisms in biofilm communities can perform intercellular actions to adapt to changes in environmental parameters. Many biofilms of bacteria are considered to be major problematic for human's health, environment and the industry. Biofilms are found everywhere in nature, as mucous membranes on rocks or other objects in water. Bacteria are protected from many harmful agents such as UV light, antibiotics and other antimicrobial agents as long as they are inside biofilms (1).

Approximately, 99.9\% of bacteria have the capability to produce biofilms on a broad spectrum of levels such as biological and inanimate levels. Biofilm producing has been reported in the large number of bacterial species such as Enterobacter cloacae, Klebsiella pneumonia, Pseudomonas aeruginosa, Escherichia coli, Staphylococcus epidermidis, Staphylococcus aureus, Haemophilus influenza, Actinomyces israelii, Burkholderia cepacia (2-5).

In the health concept, biofilms cause more than $80 \%$ 
of hospital infections. Biofilms play a role in the development of diseases related to several devices such as central venous catheters, central venous catheter needless connectors, contact lenses, endotracheal tubes, intrauterine devices, mechanical heart valves, pacemakers, peritoneal dialysis catheters, prosthetic joint, tympanostomy tubes, urinary catheters, voice prostheses $(6,7)$.

Several reasons, including the acquisition of genetic elements associated with antibiotic resistance have been responsible for the resistance of biofilms to antibiotic therapy and have caused some problems for their elimination $(8,9)$. Therefore, preventing biofilm production and their microbial colonies is a key to successful strategy against infections related to medical equipment (10). Recently, the development of anti-microbial agents and coatings impregnated with substances such as antibiotics, silver, nitric oxide, and newly antimicrobial peptides have been expanding rapidly (11).

However, many of these coatings had cytotoxicity effects. Anti-microbial enzymes are emerging as a new generation of anti-microbial agents. Among these enzymes, glucose oxidase is used to produce $\mathrm{H} 2 \mathrm{O} 2$ as a known antimicrobial agent in the food industry. $\mathrm{H} 2 \mathrm{O} 2$ is a strong adherent oxidizing agent used in low concentrations as an antiseptic. Cellobiose dehydrogenase (CDH) is an extracellular enzyme produced by various wood-degrading fungi. It oxidizes soluble cellodextrins, mannodextrins and lactose efficiently to their corresponding lactones by a pingpong mechanism using a wide spectrum of electron acceptors, including quinones, phenoxyradicals, $\mathrm{Fe}^{3+}, \mathrm{Cu}^{2+}$ and triiodide ion. Founding an alternative treatment of infections related to biofilm-producing bacteria may be beneficial to clinicians (12-15).

\section{Objectives}

Among the new technologies based on biotechnology, enzymes are developing as a new generation of antimicrobial agents. Therefore, this study aimed to determine the minimum inhibitory concentration of cellulose dehydrogenase enzyme from Aspergillus niger strains on biofilm of clinical isolates of Staphylococcus epidermidis and Pseudomonas aeruginosa.

\section{Methods}

\subsection{Fungal Strains and Culture}

Five standard strains of Aspergillus niger were purchased from the Scientific and Industrial Research Organization of Iran. Each strain was cultured onto Cezapek dox agar (Merk.co1054380500) and incubated at $26^{\circ} \mathrm{C}$ and $35^{\circ} \mathrm{C}$ until the growth was obtained. The plates were considered during 4 weeks. Aspergillus niger was identified based on colony morphology and microscopic appearance (16).

A volume of 2 - $5 \mathrm{~mL}$ distilled water containing $0.1 \%$ tween 80 sterile was added to tubes containing fresh colonies of Aspergillus niger. Then, this suspension was divided into sterile $15-\mathrm{mL}$ falcons and the number of fungal cells was counted using Neubauer chamber. (Suspension should be containing $10^{6}$ cells $/ \mathrm{mL}$ ). Then, dilution of 0.001 of the suspensions was inoculated in Sabouraud dextrose agar containing chloramphenicol and the number of colonies was counted (17).

\subsubsection{Zymogram Method for Screening of $C D H$}

To select the strain of Aspergillus niger with the highest enzyme activity in the production of cellobiose dehydrogenase, a solid screening medium was prepared. This medium contained 2, 6-Dichloroindophenol, cellobiose, the Cezapek dox agar, chloramphenicol and cellulose. Twenty $\mu \mathrm{l}$ of spore suspension of fungal strains were inoculated in the well, which was prepared in each plate. Plates were stored at $25^{\circ} \mathrm{C}$ for 7 - 10 days. Following glutathione sulfate dehydrogenase production by Aspergillus niger, and the reduction of the 2, 6-DCPIP in the culture, a clear halo was produced around colony that is directly related to the amount of enzyme produced. Therefore, the diameter of the transparent halo formed around each isolate was measured after the incubation period. The isolate that produced the greatest diameter of halo were selected as suitable isolates for the next steps. Fungi selected by this method were used to determine with high enzyme production in a specific culture medium (17).

\subsubsection{Enzyme Assay for CDH Activity}

The activity of $\mathrm{CDH}$ was measured according to Shams-Ghahfarokhi et al. study in 2004. Suitable environmental compositions for measuring the activity of the $\mathrm{CDH}$ (cellulose-containing mineral liquid culture medium) were as follows: $\mathrm{CoCl}_{2}, \mathrm{MnSO}_{4} \cdot 7 \mathrm{H}_{2} \mathrm{O}, \mathrm{FeSO}_{4} .7 \mathrm{H}_{2} \mathrm{O}$, $\mathrm{ZnSO}_{4} .7 \mathrm{H}_{2} \mathrm{O}, \mathrm{CaCl}_{2}$, yeast extract, $7 \mathrm{H}_{2} \mathrm{O} \mathrm{MgSO}{ }_{4}, \mathrm{KH}_{2} \mathrm{PO}_{4}$, $\left(\mathrm{NH}_{4}\right) 2 \mathrm{SO}_{4}$, cellulose. The amount of 106 fungal cells per $\mathrm{mL}$ of culture medium was added in sterile conditions and maintained for 14 days at $28^{\circ} \mathrm{C}$. Mycelia from selected Aspergillus niger were isolated from medium. In order to measure the activity of extracellular $\mathrm{CDH}, 5 \mu \mathrm{L}$ of the sample was added to $50 \mu \mathrm{L}$ 2,6-DCPIP ( $2 \mathrm{mM}$ ), and then 0.9 $\mathrm{mL}$ of a $2.5 \mathrm{mM}$ cellobiose solution was added. In order to prepare a control sample, instead of adding a cellobiose solution, a phosphate buffer solution was used and optical density of the samples was read at $600 \mathrm{~nm}$ (18).

The blank contained all the above materials except enzyme solution that substituted with an equal amount of 
phosphate buffer. The reaction was started by the addition of enzyme solution and the decrease in $600 \mathrm{~nm}$ absorbance was monitored during the first $5 \mathrm{~min}$ at $37^{\circ} \mathrm{C}$. The specific activity was presented as unit/mg protein. Protein concentration was measured by the dye-binding method of Bradford using bovine serum albumin as standard. The final concentration of CDH was $364 \mathrm{U} / \mathrm{mL}$ (19).

\subsection{Bacterial Strains and Culturing}

Bacterial strains were collected from Firoozgar Valiasr Hospital. Only, 42 strains were proper and could produce biofilms. Twenty-four strains of Staphylococcus epidermidis and 18 strains of Pseudomonas aeruginosa were validated with conventional phenotypic and biochemical tests (20). The S. epidermidis strains, ATCC 12228 (American Type Culture Collection) and ATCC 35984 (biofilmproducer) were used (21). Pseudomonas aeruginosa PAO1 (biofilm-producing) and P. aeruginosa ATCC 27853 (nonbiofilm-producing) were used as controls (22).

\subsubsection{Measurement of Biofilm Production}

To investigate CDH ability to consume ExPS as a substrate, overnight cultures of studied strains were grown in TSB at $37^{\circ} \mathrm{C}$. After preparing McFarland concentration, 150 $\mu \mathrm{L}$ of this suspension was poured into 96-well microplates and placed at $37^{\circ} \mathrm{C}$ during 24 hours. Then, the supernatant was removed and the wells were gently washed 3 times with physiological saline $(0.9 \% \mathrm{NaCl})$ and the microplate was reversed at $65^{\circ} \mathrm{C}$ to dry. Better biofilm was used for $96 \%$ ethanol at $100 \mu \mathrm{L} .100 \mu \mathrm{L}$ ethanol $96 \%$ was added, then after $15 \mathrm{~min}$, the alcohol was removed and the microplate was dried in air. Subsequently, $150 \mu \mathrm{L}$ of $2 \%$ crystal violet was added to all wells and after 20 minutes was washed and excess materials were removed from the wells by tapping. Then, $150 \mu \mathrm{L}$ of $33 \%$ acetic acid was added to the wells to release the bonded color to the biofilm to the microplate surface. Optical absorption (OD) was read at $550 \mathrm{~nm}$ wavelength using ELISA reader (23).

\subsubsection{Antibiofilm Activities of CDH by Microtiter Plate (MTP) As- say}

Quantitative biofilm detachment in vitro quantification of biofilm formation was monitored by MTP assay using crystal violet dye and measured spectrophotometrically. Crystal violet dye not only stains but also screens a very small amount of adhered molecules that alter biofilm formation. After $12 \mathrm{~h}$ treatment, strains exhibited a reduction in biofilm formation when compared to control. The apparent 50\% inhibitory concentration (IC50) of cellobiose in liquid medium was determined by incubating different cellobiose concentrations with Pseudomonas aeruginosa and Staphylococcus epidermidis in 96-well plates. Trypticase soy broth (TSB) $(100 \mu \mathrm{L})$ was pipetted into each well, followed by $100 \mu \mathrm{L}$ of $50 \mathrm{mM}$ cellobiose. Serial dilutions of cellobiose ranging from 50, 25, 12.5, 6.125, 3.175, 1.56, $0.078 \mathrm{mM}$ were achieved by transferring $100 \mu \mathrm{L}$ in each consecutive lane. In the end, a bacterial suspension (Pseudomonas aeruginosa and Staphylococcus epidermidis) containing $5 \mu \mathrm{L}$ of $10^{5} \mathrm{CFU} / \mathrm{mL}$ was added, followed by $10 \mu \mathrm{L}$ of $364 \mathrm{U} / \mathrm{mL} \mathrm{CDH}$. The respective controls, e.g. CDH only, negative and sterile control, were also prepared in the other lanes. Plates were incubated at $37^{\circ} \mathrm{C}$ for $24 \mathrm{~h}$ and the OD 520 was measured every $30 \mathrm{~min}$ in a plate reader. The apparent IC50 value was defined as the concentration of cellobiose inhibiting growth by $50 \%$ compared with the negative control. All determinations were performed in triplicate (23, 24).

\section{Results}

Out of the 42 bacteria gathered from Firoozgar Vali Asr Hospital during June 2017 - 2018, which 24 strains were Staphylococcus epidermidis (57\%) and 18 strains were Pseudomonas aeruginosa (43\%). There were isolated from blood. In order to select Aspergillus niger $\mathrm{CDH}$ producer, all 5 isolates were examined in a 2, 6-dichlorophenolindophenol (DCPIP) screening medium. When DCPIP was oxidized, blue color around fungal colonies was appeared (Figure 1).

Based on zymogram test, isolate No. 5010 was selected as the best isolate of Aspergillus niger for production of extracellular $\mathrm{CDH}$ enzymes and used in subsequent stages of the study.

The activity of $\mathrm{CDH}$ was measured and $\mathrm{CDH}$ activity with $364 \mathrm{U} / \mathrm{mg}$ final concentration with a standard deviation were obtained. As it is indicated in Table 1, the results of biofilm formation were classified as biofilm-negative (-), weakly (+), moderately (++), and strongly adherent (+++). Mean and standard deviation based on the strength of biofilm formation in microtiter plate is shown in Table 2 (25).

Table 1. Classification of Bacteria Based on the Strength of Biofilm Formation in Microtiter Plate

\begin{tabular}{lcc}
\hline Biofilm Class & Status & Results \\
\hline If $\mathbf{O D} \leq \mathbf{O D ~ c}$ & Non-adherent & $(-)$ \\
If $\mathbf{O D} \mathbf{C}<\mathbf{O D} \leq \mathbf{2 x}$ OD c & Weakly adherent & $(+)$ \\
If $\mathbf{2 x}$ OD c $<\mathbf{O D} \leq \mathbf{4 x}$ OD c & Moderately adherent & $(++)$ \\
If $\mathbf{4 x}$ OD $\mathbf{~}<\mathbf{O D}$ & Strongly adherent & $(+++)$ \\
\hline
\end{tabular}

Mean and standard deviation about the strength of biofilm formation in microtiter plate assay, in Pseudomonas aeruginosa strains was $0.672 \pm 0.246$ and in 

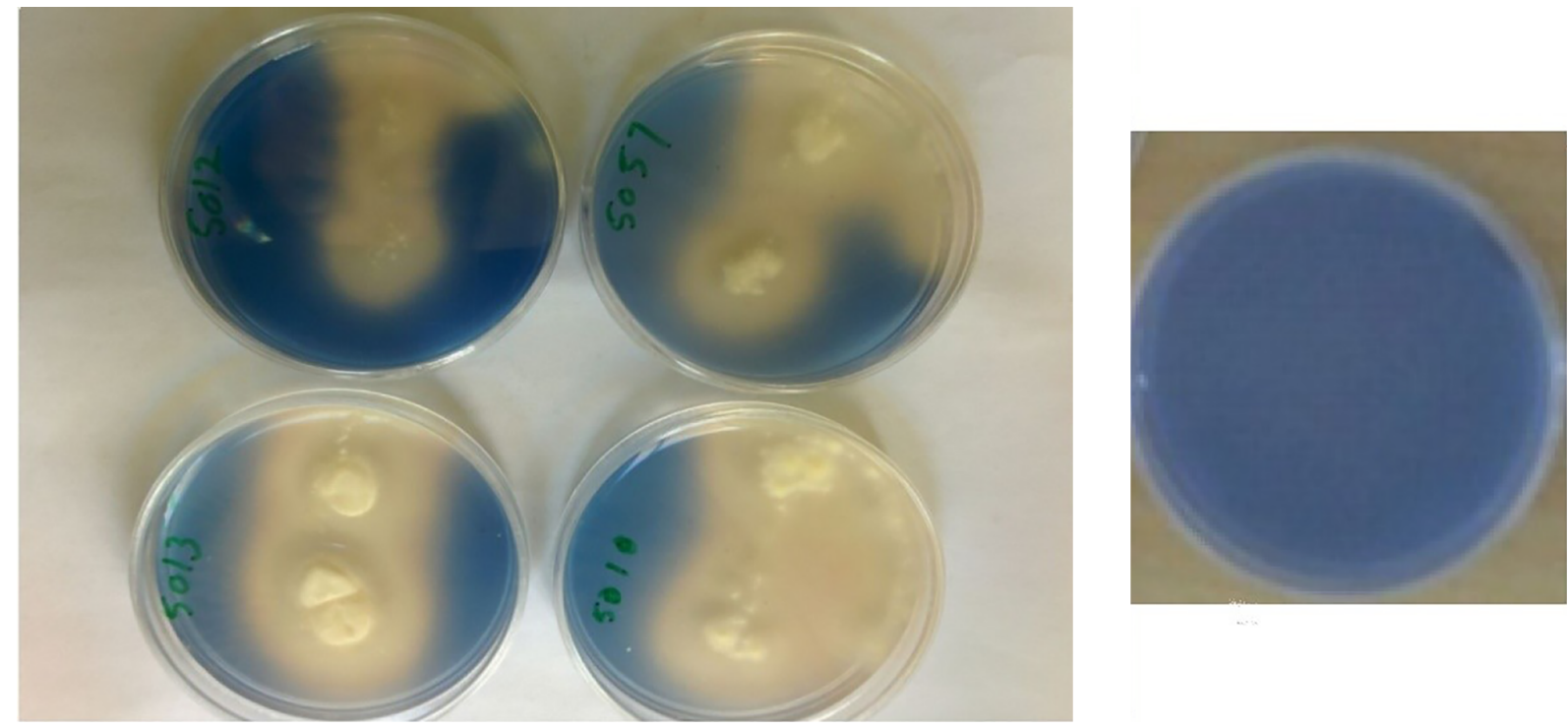

Figure 1. Evaluation of $\mathrm{CDH}$ production by zymogram method in Aspergillus niger strains

Staphylococcus epidermidis strains $0.668 \pm 0.245$, which was not statistically significant $(\mathrm{P}=0.955)$. Classification of bacteria based on the strength of the biofilm formation status in microtiter plate assay was $58.3 \%$ moderately adherent in Staphylococcus epidermidis and $27.8 \%$ in Pseudomonas aeruginosa strains, which was not statistically significant based on t-test $(\mathrm{P}=0.955)$.

Of the 42 bacterial samples, 24 strains were Staphylococcus epidermidis, 18 strains were Pseudomonas aeruginosa. Out of 24 bacterial strains of Staphylococcus epidermidis, 7 strains were weakly adherent (29\%), 14 strains moderately adherent (58\%), and 3 strains strongly adherent (13\%). Out of 18 pseudomonas aeruginosa strains, 9 strains were weakly adherent (50\%), 4 strains moderately adherent (23\%) and 5 strains strongly adherent (27\%).

Growth inhibition of Staphylococcus epidermidis and Pseudomonas aeruginosa in liquid cultures as a function of cellobiose concentration in the presence of $\mathrm{CDH}$ was considered. Out of 42 strains, $\mathrm{CDH}$ had inhibitory concentration only on 34 strains (Figure 2 ).

Out of 24 pseudomonas aeruginosa strains, 4 strains (22.2\%) and out of 18 Staphylococcus epidermidis 4 strains (16.7\%) did not have any minimum inhibitory concentration. Fisher exact test revealed that there were no significant differences between pseudomonas aeruginosa strains and Staphylococcus epidermidis $(\mathrm{P}=0.71)$.

In fact, IC50 is a concentration in which $50 \%$ of growth is prevented by $\mathrm{CDH}$ compared with negative control. According to the results of IC50 shown in Figure 2, the most effective dilution of cellobiose on growth inhibition of
Staphylococcus epidermidis and Pseudomonas aeruginosa in liquid cultures as a function of cellobiose concentration in the presence of cellobiose dehydrogenase was in 12.5 $\mu \mathrm{g} / \mathrm{mL}$.

\section{Discussion}

The bacterial cell wall has a shape-giving function and protects the cells from osmotic disruption. In addition, several antimicrobial agents fail to penetrate the biofilms mainly due to the presence of ExPS, which act as a barrier and protect the bacterial cells. Owing to the heterogeneous nature of ExPS, a mixture of enzymes might be necessary for efficient degradation of bacterial biofilms. Previous reports have shown that enzymes' mixture can degrade the ExPS of the bacterial biofilms. Enzymes degrade the biofilms directly by destroying the physical integrity of the extracellular polymeric substances through weakening the proteins, carbohydrate and lipid components of the extracellular polymeric substances (8, 26-30).

Microbial biofilms are now a serious medical problem. Because biofilms have become a major concern today, and bacteria indicate strong resistance to antibiotics and other disinfectants through these structures. Several antimicrobial enzymes targeting different cellular components and biofilms are intensively being investigated with some products already commercialized in the health, food and biomedical industry. Although generally, enzymes are effective as antimicrobial agents, successful removal of complex biofilms requires the use of a complex enzyme for- 


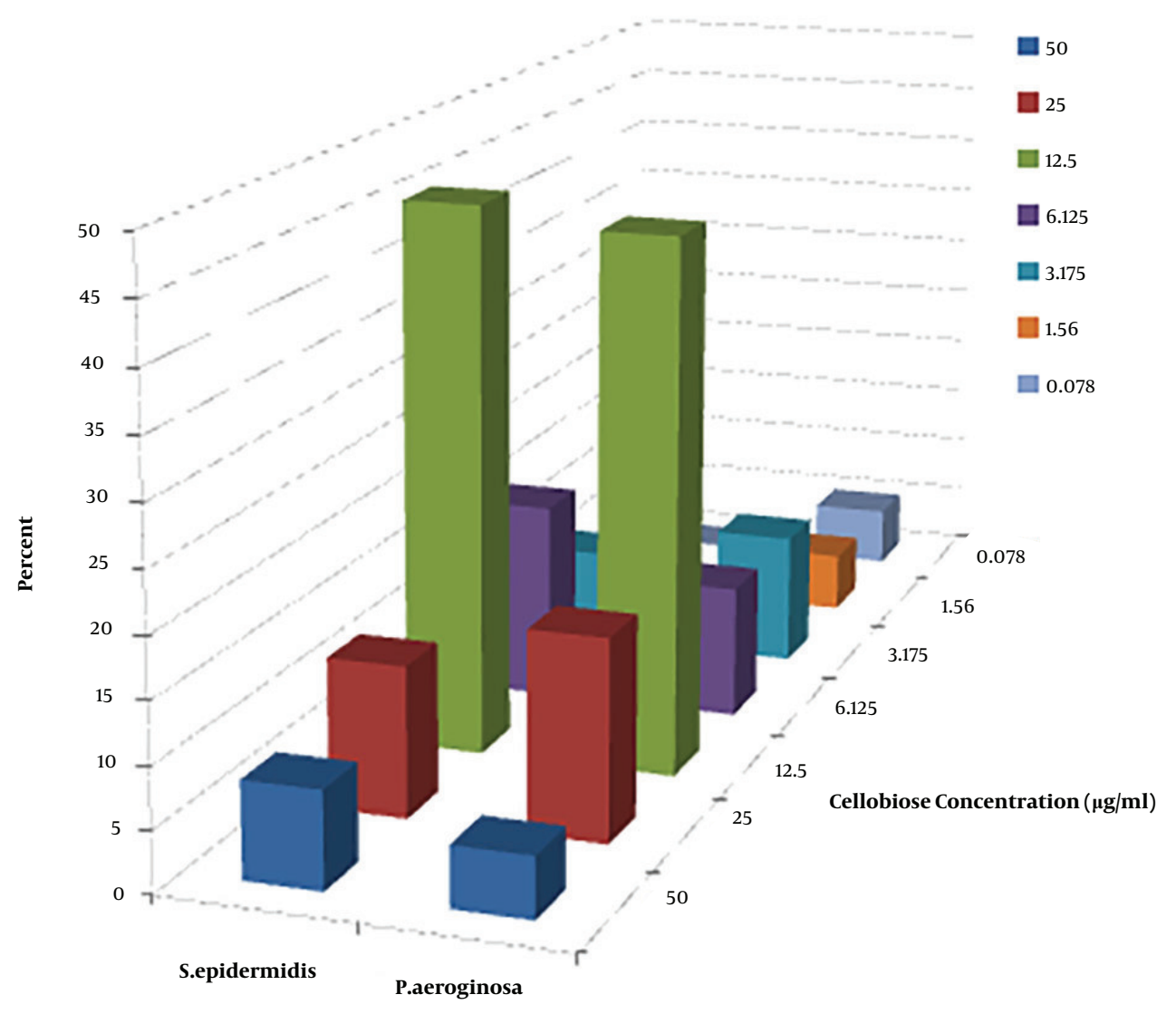

Figure 2. Growth inhibition of S. epidermidis and P. aeruginosa in liquid cultures as a function of cellobiose concentration in the presence of cellobiose dehydrogenase

mulation containing DNase to degrade extracellular DNA, $\mathrm{CDH}$ extracellular polysaccharides, proteases to hydrolyze proteins as well as anti-quorum sensing enzymes to prevent biofilm formation. A novel in situ antibiofilm and antimicrobial system based on the ability of $\mathrm{CDH}$ to produce $\mathrm{H} 2 \mathrm{O} 2$ in the presence of cellobiose was successfully developed (14).

The first and only report on the production of this enzyme in the Aspergillus niger species of was reported by Duarte et al. in 1999. The researcher showed that by using the zymogram method, different isolates of different fungal species, including different species of Aspergillus niger, could be studied in terms of the production of $\mathrm{CDH}$ enzymes. They showed that the CDH enzyme in the Aspergillus niger fungus is an extracellular enzyme and is secreted into the culture medium (31).

We determined MIC of CDH enzyme extracted from Aspergillus niger on the biofilm of Staphylococcus epidermidis and Pseudomonas aeruginosa isolated from clinical specimens.
Croes et al. in 2009, studied Staphylococcus aureus biofilm formation at the physiologic glucose concentration based on the $S$. aureus lineage. They found the adherence to polystyrene surfaces under physiologic glucose concentration (0.1\%) was dependent on the clonal lineage (32). In fact, biofilm inhibition more closely correlated with increasing substrate concentration. When the concentration of the substrate increased, the biofilm inhibition decreased. In our study, we reported the highest concentration of cellobiose was in $12.5 \mu \mathrm{g} / \mathrm{mL}$. We also found that increasing biofilm inhibition was associated with increasing substrate concentrations. When the concentration of the substrate is greater than $12.5 \mu \mathrm{g} / \mathrm{mL}$, biofilm was reduced. We also found that inhibition of $\mathrm{CDH}$ was increased by the presence of cellobiose as a substrate.

$\mathrm{CDH} /$ cellobiose dilution was able to oxidize enzymatically ExPS of Staphylococcus epidermidis and Pseudomonas aeruginosa leading to the production of $\mathrm{H} 2 \mathrm{O} 2$. These complexes of $\mathrm{CDH} /$ cellobiose were known to exhibit antimicrobial activities by destroying the biofilm matrix through 
Table 2. Mean and Standard Deviation Based on the Strength of Biofilm Formation in Microtiter Plate Assay (MTP)

\begin{tabular}{|c|c|c|}
\hline Strain Number & Mean \pm SD & Biofilm Mode \\
\hline S.1 & $0.811 \pm 0.028$ & Moderately adherent \\
\hline S.2 & $0.556 \pm 0.028$ & Moderately adherent \\
\hline S.3 & $0.621 \pm 0.028$ & Moderately adherent \\
\hline S.4 & $0.567 \pm 0.028$ & Moderately adherent \\
\hline S.5 & $0.908 \pm 0.028$ & Moderately adherent \\
\hline S.6 & $1.08 \pm 0.028$ & Strongly adherent \\
\hline S.7 & $0.631 \pm 0.028$ & Moderately adherent \\
\hline S.8 & $0.528 \pm 0.028$ & Moderately adherent \\
\hline S.9 & $0.564 \pm 0.028$ & Moderately adherent \\
\hline S.15 & $0.738 \pm 0.028$ & Moderately adherent \\
\hline S.16 & $0.721 \pm 0.028$ & Moderately adherent \\
\hline S.17 & $0.612 \pm 0.028$ & Moderately adherent \\
\hline S.18 & $0.740 \pm 0.028$ & Moderately adherent \\
\hline S.19 & $0.811 \pm 0.028$ & Moderately adherent \\
\hline S.20 & $1.253 \pm 0.028$ & Strongly adherent \\
\hline S.21 & $1.214 \pm 0.028$ & Strongly adherent \\
\hline S.22 & $0.621 \pm 0.028$ & Moderately adherent \\
\hline S.23 & $0.438 \pm 0.028$ & Weakly adherent \\
\hline S.24 & $0.52 \pm 0.028$ & Weakly adherent \\
\hline S.25 & $0.419 \pm 0.028$ & Weakly adherent \\
\hline S.26 & $0.480 \pm 0.028$ & Weakly adherent \\
\hline S.28 & $0.434 \pm 0.028$ & Weakly adherent \\
\hline S.29 & $0.335 \pm 0.028$ & Weakly adherent \\
\hline S.30 & $0.429 \pm 0.028$ & Weakly adherent \\
\hline P.10 & $0.485 \pm 0.041$ & Weakly adherent \\
\hline P.11 & $0.975 \pm 0.041$ & Strongly adherent \\
\hline P.12 & $0.608 \pm 0.041$ & Moderately adherent \\
\hline P.13 & $0.523 \pm 0.041$ & Moderately adherent \\
\hline P.14 & $0.447 \pm 0.041$ & Weakly adherent \\
\hline P.27 & $0.531 \pm 0.041$ & Weakly adherent \\
\hline P.31 & $0.618 \pm 0.041$ & Moderately adherent \\
\hline P.32 & $1.004 \pm 0.041$ & Strongly adherent \\
\hline P.33 & $0.468 \pm 0.041$ & Weakly adherent \\
\hline P.34 & $0.63 \pm 0.041$ & Moderately adherent \\
\hline P.35 & $0.494 \pm 0.041$ & Weakly adherent \\
\hline P.36 & $0.52 \pm 0.041$ & Weakly adherent \\
\hline P.37 & $1.126 \pm 0.041$ & Strongly adherent \\
\hline P.38 & $0.566 \pm 0.041$ & Weakly adherent \\
\hline P.39 & $0.490 \pm 0.041$ & Weakly adherent \\
\hline P.40 & $0.980 \pm 0.041$ & Moderately adherent \\
\hline P.41 & $0.497 \pm 0.041$ & Weakly adherent \\
\hline P.42 & $1.140 \pm 0.041$ & Strongly adherent \\
\hline
\end{tabular}

Abbreviations: P, Pseudomonas aeruginosa; S, Staphylococcus epidermidis; SD, standard deviation

linked glycosides cleavage of ExPS. Hydrolysis of polysaccharides by this enzyme increases the number of terminal reducing sugars as substrates for $\mathrm{CDH}$ as well as destabilizes the biofilm. In addition, biofilm hydrolysis leads to its destabilization and failure to protect microorganisms from antimicrobial agents $(14,33,34)$.

An increase of biofilm inhibition with the increase of the substrate for $\mathrm{CDH}$ was expected. The inhibition of biofilm formation was decreased at a substrate concentration of $6.25 \mu \mathrm{g} / \mathrm{mL}$ cellobiose. The reason could be explained by the metabolization of cellobiose by the cells which were embedded in the bacterial biofilms was faster than the enzymatical reaction (34).

\subsection{Conclusions}

Based on the results of this study, it can be concluded that the $\mathrm{CDH}$ enzyme can be a candidate as an antimicrobial agent. Interestingly, $\mathrm{CDH}$ was also able to produce $\mathrm{H} 2 \mathrm{O} 2$ during oxidation of ExPS formed by microorganisms in cellobiose absence. To develop the antimicrobial system for application further studies should be carried out to exclude the effect of the $\mathrm{CDH}$ substrates to support the growth of microorganisms.

\section{Acknowledgments}

We thank Mrs. Agahazadeh and Mrs. Ebrahimi for their support.

\section{Footnotes}

Authors' Contribution: All authors contributed to the development of the protocol, data analysis, and preparation of the manuscript, study concept, and design.

Conflict of Interests: The authors declare no conflict of interest regarding the publication of this article.

Funding/Support: This work was supported by School of Allied Medical Sciences, Shahid Beheshti University of Medical Sciences, Tehran, Iran.

\section{References}

1. Flemming HC, Wingender J. The biofilm matrix. Nat Rev Microbiol. 2010;8(9):623-33. doi: 10.1038/nrmicro2415. [PubMed: 20676145].

2. Haussler S, Parsek MR. Biofilms 2009: New perspectives at the heart of surface-associated microbial communities. I Bacteriol 2010;192(12):2941-9. doi: 10.1128/JB.00332-10. [PubMed: 20382760] [PubMed Central: PMC2901683].

3. Fux CA, Costerton JW, Stewart PS, Stoodley P. Survival strategies of infectious biofilms. Trends Microbiol. 2005;13(1):34-40. doi: 10.1016/j.tim.2004.11.010. [PubMed:15639630].

4. Naves P, del Prado G, Huelves L, Rodriguez-Cerrato V, Ruiz V, Ponte $\mathrm{MC}$, et al. Effects of human serum albumin, ibuprofen and N-acetylL-cysteine against biofilm formation by pathogenic Escherichia coli strains. J Hosp Infect. 2010;76(2):165-70. doi: 10.1016/j.jhin.2010.05.011. [PubMed: 20615578]

5. Percival SL, Kite P. Intravascular catheters and biofilm control. J Vasc Access. 2007;8(2):69-80. [PubMed: 17534791]. 
6. Vasudevan R. Biofilms: Microbial cities of scientific significance. JMicrobiol Exp. 2014;1(3). doi: 10.15406/jmen.2014.01.00014.

7. Patel FM, Goswami PN, Khara R. Detection of biofilm formation in device associated clinical bacterial isolates in cancer patients. Sri Lankan J Infect Dis. 2016;6(1):43. doi: 10.4038/sljid.v6i1.8086.

8. Lequette $Y$, Boels $G$, Clarisse M, Faille C. Using enzymes to remove biofilms of bacterial isolates sampled in the food-industry. Biofouling. 2010;26(4):421-31. doi: 10.1080/08927011003699535. [PubMed: 20198521].

9. Campoccia D, Montanaro L, Speziale P, Arciola CR. Antibiotic-loaded biomaterials and the risks for the spread of antibiotic resistance following their prophylactic and therapeutic clinical use. Biomaterials. 2010;31(25):6363-77. doi: 10.1016/j.biomaterials.2010.05.005. [PubMed: 20542556].

10. Regev-Shoshani G, Ko M, Crowe A, Av-Gay Y. Comparative efficacy of commercially available and emerging antimicrobial urinary catheters against bacteriuria caused by E. coli in vitro. Urology. 2011;78(2):334-9. doi: 10.1016/j.urology.2011.02.063. [PubMed: 21820571].

11. Li X, Li P, Saravanan R, Basu A, Mishra B, Lim SH, et al. Antimicrobial functionalization of silicone surfaces with engineered short peptides having broad spectrum antimicrobial and salt-resistant properties. Acta Biomater. 2014;10(1):258-66. doi: 10.1016/j.actbio.2013.09.009. [PubMed: 24056098].

12. Henriksson G, Johansson G, Pettersson G. A critical review of cellobiose dehydrogenases. J Biotechnol. 2000;78(2):93-113. doi: 10.1016/s0168-1656(00)00206-6. [PubMed: 10725534].

13. Nyanhongo GS, Sygmund C, Ludwig R, Prasetyo EN, Guebitz GM. An antioxidant regenerating system for continuous quenching of free radicals in chronic wounds. Eur J Pharm Biopharm. 2013;83(3):396-404. doi: 10.1016/j.ejpb.2012.10.013. [PubMed: 23153671].

14. Thallinger B, Prasetyo EN, Nyanhongo GS, Guebitz GM. Antimicrobial enzymes: An emerging strategy to fight microbes and microbial biofilms. Biotechnol J. 2013;8(1):97-109. doi: 10.1002/biot.201200313. [PubMed: 23281326].

15. Navidinia M, Goudarzi M, Rameshe SM, Farajollahi Z, Ebadi Asl P, khosravi SZ, et al. Molecular characterization of resistance genes in MDR-ESKAPE pathogens. J Pure Appl Microbiol. 2017;11(2):779-92. doi: 10.22207/jpam.11.2.17

16. Kaya AD, Kiraz N. In vitro susceptibilities of Aspergillus spp. causing otomycosis to amphotericin $\mathrm{B}$, voriconazole and itraconazole. Mycoses. 2007;50(6):447-50. doi: 10.1111/j.1439-0507.2007.01409.x. [PubMed: 17944704].

17. Kracher D, Ludwig R. Cellobiosedehydrogenase: Ein essentielles Enzym für den Lignozelluloseabbau in der Natur - Eine Übersicht [Cellobiose dehydrogenase: An essential enzyme for lignocellulose degradation in nature - A review]. J Land Manag Food Environ. 2016;67(3):145-63. doi: 10.1515/boku-2016-0013.

18. Shams Ghahfarokhi M, Fazli A, Lotfi A, Razzaghi Abyaneh M. Cellobiose dehydrogenase production by the genus Cladosporium. Iran Biomed J. 2004;8(2):107-11.

19. Bradford MM. A rapid and sensitive method for the quantitation of microgram quantities of protein utilizing the principle of proteindye binding. Anal Biochem. 1976;72(1-2):248-54. doi: 10.1016/00032697(76)90527-3.

20. Mahon CR, Lehman DC. Textbook of diagnostic microbiology. 6th ed. Elsevier eBook on Vital Source; 2017.
21. Okajima Y, Kobayakawa S, Tsuji A, Tochikubo T. Biofilm formation by Staphylococcus epidermidis on intraocular lens material. Invest Ophthalmol Vis Sci. 2006;47(7):2971-5. doi: 10.1167/iovs.05-1172. [PubMed: 16799041].

22. Perez LR, Costa MC, Freitas AL, Barth AL. Evaluation of biofilm production by Pseudomonas aeruginosa isolates recovered from cystic fibrosis and non-cystic fibrosis patients. Braz J Microbiol. 2011;42(2):476-9. doi: 10.1590/S1517-838220110002000011. [PubMed: 24031658]. [PubMed Central: PMC3769813].

23. Thallinger B, Argirova M, Lesseva M, Ludwig R, Sygmund C, Schlick A et al. Preventing microbial colonisation of catheters: antimicrobial and antibiofilm activities of cellobiose dehydrogenase. Int J Antimicrob Agents. 2014;44(5):402-8. doi: 10.1016/j.ijantimicag.2014.06.016. [PubMed: 25176584].

24. Kumar P, Selvi SS, Govindaraju M. In vitro anti-biofilm and antibacterial activity of Junceella juncea for its biomedical application. Asian Pac J Trop Biomed. 2012;2(12):930-5. doi: 10.1016/S22211691(13)60002-7. [PubMed: 23593571]. [PubMed Central: PMC3621467].

25. Ma S, Preims M, Piumi F, Kappel L, Seiboth B, Record E, et al. Molecular and catalytic properties of fungal extracellular cellobiose dehydrogenase produced in prokaryotic and eukaryotic expression systems. Microb Cell Fact. 2017;16(1):37. doi: 10.1186/s12934-017-0653-5. [PubMed: 28245812]. [PubMed Central: PMC5331742].

26. Singh V, Verma N, Banerjee B, Vibha K, Haque S, Tripathi CKM. Enzymatic degradation of bacterial biofilms using Aspergillus clavatus MTCC 1323. Microbiology. 2015;84(1):59-64. doi: 10.1134/s0026261715010130.

27. Pelczar M, Chan JE, Krieg NR. Microbiology. New York: Mc GrawHill; 1993.

28. Naumann D. Infrared spectroscopy in microbiology, in encyclopedia of analytical chemistry. Chichester: Wiley; 2000. p.102-31.

29. Johansen C, Falholt P, Gram L. Enzymatic removal and disinfection of bacterial biofilms. Appl Environ Microbiol.1997;63(9):3724-8. [PubMed: 9293025]. [PubMed Central: PMC168680].

30. Xavier JB, Picioreanu C, Rani SA, van Loosdrecht MCM, Stewart PS. Biofilm-control strategies based on enzymic disruption of the extracellular polymeric substance matrix-a modelling study. Microbiology. 2005;151(Pt 12):3817-32. doi: 10.1099/mic.0.28165-0. [PubMed: 16339929].

31. Duarte IC, Costa-Ferreira M, Sena-Martins G. Cellobiose dehydrogenase. Possible roles and importance for pulp and paper biotechnology. Bioresour Technol. 1999;68(1):43-8. doi: 10.1016/s09608524(98)00080-7.

32. Croes S, Deurenberg RH, Boumans ML, Beisser PS, Neef C, Stobberingh EE. Staphylococcus aureus biofilm formation at the physiologic glucose concentration depends on the S. aureus lineage. BMC Microbiol. 2009;9:229. doi: 10.1186/1471-2180-9-229. [PubMed: 19863820]. [PubMed Central: PMC2774858]

33. Glinel K, Thebault P, Humblot V, Pradier CM, Jouenne T. Antibacterial surfaces developed from bio-inspired approaches. Acta Biomater. 2012;8(5):1670-84. doi: 10.1016/j.actbio.2012.01.011. [PubMed: 22289644].

34. Pricelius S, Ludwig R, Lant N, Haltrich D, Guebitz GM. Substrate specificity of Myriococcum thermophilum cellobiose dehydrogenase on mono-, oligo-, and polysaccharides related to in situ production of H2O2. Appl Microbiol Biotechnol. 2009;85(1):75-83. doi: 10.1007/s00253009-2062-0. [PubMed: 19506859]. 